\title{
Investigation of effect of the number of ground control points and distribution on adjustment at WorldView-2 Stereo images \#
}

\author{
Omer Mutluoglu *1, Murat Yakar, Haci Murat Yilmaz
}

Accepted $15^{\text {th }}$ August 2014

\begin{abstract}
Nowadays, Very High Resolution Satellite (VHRS) images have been used for many applications intensively. Using of the digital satellite images in relevant approaches may give more accurate ideas about the researched fields. Besides, different methods could be used for production of maps from relevant digital data in many scientific disciplines. One of these methods is to use VHRS images. The most importance reason of using the maps, which are derived from VHRS images, is accuracy of data. To obtain maps from VHRS images or use VHRS images as map, the VHRS images required rectification. For a accurate rectification process, Ground Control Points (GCPs) must be marked in the field. In this study the effect of number of GCP and distrubition on the surface has been investigated on stereo WorldView-2 (WV-2) at rectification of VHRS images. The effect of distribution of control points at the terrain has seen to be more effective than the effect of number of control points upon the adjustment results.
\end{abstract}

Keywords: WorldView-2, Ground Control Point, Check Point, Rectification, Resolution, VHRS.

\section{Introduction}

High resolution satellite images, as less than $1 \mathrm{~m}$. resolution are used in many fields. For example, updating existing maps, land use mapping, urban planning, disaster monitoring, and so on. To use high resolution satellite images in such fields, they had to be rectified. Rectification process is done by points, which coordinates are known in both land and image. The selected points may indicate either measured points in the field or/and can be designated as visible points in images. Sometimes, these points may represent; road cross, painting objects, etc. Points which are set up in the field are either acquired from existing maps or from image matching the research site or geodetic surveys. In this study the effect of number of GCP and distrubition on the surface has been investigated on stereo WorldView-2 (WV-2) at rectification of VHRS images.

\section{Importance of Control Points}

Acquisition of ground control points (GCPs) is particularly importance for geometric correction of high resolution satellite images. The commercial high resolution satellite image can be accurately rectified using the combination of bias-corrected rational polynomial coefficients (RPCs) and ground control points (GCPs). With a few precisely measured GCPs accurate three dimensional measurements can be made from the base level Ikonos data product. However, the accuracy of the results is dependent on the precision of the GCPs [1].

There are two approaches in geometric correction of high resolution satellite images. One of them is the bias-correction

\footnotetext{
* School of Technical Science, Architecture and Urban Planning, Selcuk Universty, Campus, 42031, Konya, Turkey

* Corresponding Author: Email: omutluoglu@selcuk.edu.tr

\# This paper has been presented at the International Conference on

Advanced Technology\&Sciences (ICAT'14) held in Antalya (Turkey), August 12-15, 2014.
}

procedure for rational polynomial coefficients (RPCs), which requires a minimum of only a single GCP, but it gives of course require RPCs. The other is affine model that requires a minimum of four GCPs per scene, though six as practical minimum would be recommended [2].

The control points could be acquired by three different methods for geometric correction in two and three dimensional of high resolution satellite images. These are; GCPs from existing maps, GCPs set up in land, GCPs from image matching.

Kadota and Takagi had used above mentioned methods in acquisition of GCPs for geometric correction of high resolution satellite image. They had achieved to best result with surveyed GCPs[3].

Dial and Grodecki had tested Ikonos stereo accuracy without ground control. They had achieved to absolute accuracy at $6.2 \mathrm{~m}$. horizontal, $10.1 \mathrm{~m}$. vertical, and found out the most relative accuracy results for points more than 3 meters [4].

Hanley and Fraser had used ground surveyed GPS points and ground control measured from the orthomosaic for two dimensional geometric correction of high resolution satellite images. They had achieved to similar results from both surveyed GPS points and orthomosaic points [5].

Dare et. all. had used ground surveyed GPS points and orthomosaic GCPs for three dimensional correction of high resolution satellite images. They had also achieved to similar results from both surveyed GPS points and orthomosaic points. The geometric corrections by using GCPs surveying in land may give most accurate results [1].

$\mathrm{Ke}$ has made the experimental study of the process of orthorectification accuracy in the analysis of images VHRS. GCP properties (shapes, distribution, the accuracy, number of GCPs) were examined [6].

Yilmaz et al., have made their work available GCPs dimensions for IKONOS satellite imagery have researched [7].

Mutluoglu et al., in their study made woldview-2 satellite images have done a study on the appropriate size of GCPs [8]. 
Table 1: Geographic coordinates of image area

\section{WorldView-2 Satellite}

The WorldView-2 (WV-2) satellite, launched by DigitalGlobe on Oct 82009 represents the first commercial imaging satellite to collect very high spatial resolution data in 8 spectral bands [9]. The images provided by the satellite can be used for applications such as mapping, land planning, disaster relief, exploration, defense and intelligence, visualization and simulation of environments, and classification. Worldview- 2 can operate at an altitude of $770 \mathrm{~km}$ with an inclination of $97.2^{\circ}$ for a maximum orbital period of 100 minutes. WorldView-2's large-area collection capabilities and rapid retargeting are two important features of the satellite. WorldView-2's advanced geopositional technology provides significant improvements in accuracy. The accuracy specification has been tightened to $6.5 \mathrm{~m}$ CE90 directly right off the satellite, meaning no processing, no elevation model and no ground control, and measured accuracy is expected to be approximately $4 \mathrm{~m}$ CE90.

WorldView-2 panchromatic resolution is $46 \mathrm{~cm}$ and multispectral resolution is $1.8 \mathrm{~m}$. Distribution and use of imagery better than $0.50 \mathrm{~m}$ GSD pan and $2.0 \mathrm{~m}$ GSD multispectral is subject to prior approval by the U.S. Government. As the first high-resolution commercial satellite to provide eight spectral bands, WorldView2 offers imagery with a high degree of detail, unlocking a finer level of analytical discernment that enables improved decisionmaking. In addition to industry-standard blue, green, red and near-infrared, WorldView-2 includes four previously unavailable bands, collected at $1.8 \mathrm{~m}$ resolution: coastal blue, yellow, red edge and near-infrared 2 . These bands offer a range of benefits to analysts, who will be able to identify a broader range of classification, (e.g. more varieties of vegetation or waterpenetrated objects), to extract more features (e.g. cotton-based camouflage from natural ground cover), to view a truer representation of colors that match natural human vision, and to track coastal changes and infractions.

WorldView-2 data is distributed in five different levels, i.e., Basic 1B, Basic Stereo Pairs, Standard 2A, Ortho-Ready Standard (OR2A), and Orthorectified.

OR2A has no topographic relief applied, making it suitable for custom orthorectification. OR2A is projected to an average elevation, either calculated from a terrain elevation model or supplied by the customer. OR2A products are recommended for geometric correction because the panchromatic and multispectral data are resampled to exactly the same geographic extents; hence, it is possible to perform pansharpening of the data before geometric correction if a pansharpened orthorectified image is desired [10],[11].

\section{Material And Method}

\subsection{Test Area}

A $(15 \mathrm{kmx} 14 \mathrm{~km})$ test area has created at surround of Konya Selcuk University Alaeddin Keykubad campus area. Application area of South and South East parts consist of the plains, Northern, North Eastern and North Western part consists of mountainous terrain. In the test area, outside the residential areas of land consist of agricultural areas and bare land. There are not height vegetation (height trees, forest). In the test area, the elevations are changing between $1000 \mathrm{~m}$. and $1700 \mathrm{~m}$. Frame area remain among the following geographic latitude and longitude and are given in table 1 .

\begin{tabular}{|l|l|l|}
\hline & latitude & longitude \\
\hline Upper left corner & $38^{\circ} 04^{\prime} 44^{\prime \prime}$ & $32^{\circ} 25^{\prime} 08^{\prime \prime}$ \\
\hline lower right corner & $37^{\circ} 56^{\prime} 46^{\prime \prime}$ & $32^{\circ} 34^{\prime} 40^{\prime \prime}$ \\
\hline
\end{tabular}

\subsection{WorldView-2 Data}

In this study, dated July 9, 2013, stereo woldview-2 (WV-2) satellite pansharpen images are used. With images (Rational Polynomial Coefficients) RPCs files are also obtained.

RPC files containe orbital parameters of the satellites (orientation, height, etc.).

RPC files have been provide model data of cameras to most software packages for 3D photogrammetric production of detail, digital elevation models and orthorectified imagery. Satellite image of the test area in figure 1 is seen. The technical characteristics of WV-2 image taken are given in table 2 .

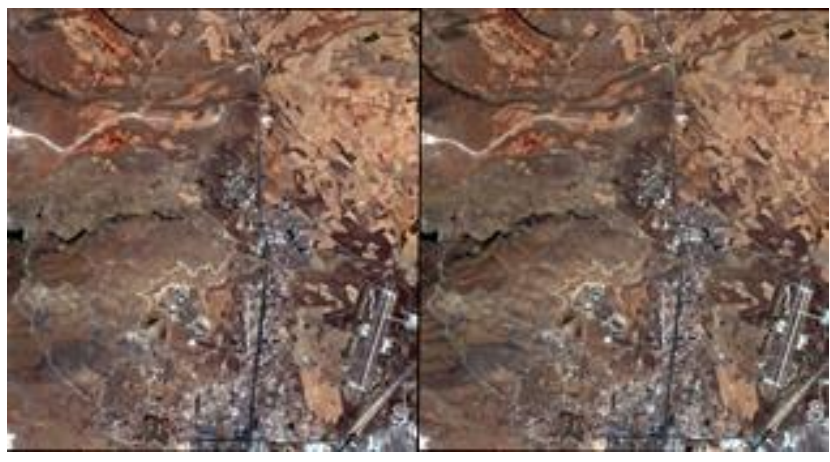

a b

b) right image
Figure. 1 a) left image

Table 2: The technical characteristics of WV-2 image taken

\begin{tabular}{|c|c|c|}
\hline Parameters & $\begin{array}{c}\text { WV-2 } \\
\text { First scene }\end{array}$ & $\begin{array}{c}\text { WV-2 } \\
\text { Second scene }\end{array}$ \\
\hline imageDescriptor & StereoOR2A & StereoOR2A \\
\hline productType & Stereo & Stereo \\
\hline bitsPerPixel & 16 & 16 \\
\hline outputFormat & GeoTIFF & GeoTIFF \\
\hline scanDirection & Forward & Forward \\
\hline \multirow[t]{2}{*}{ firstLineTime } & 09.07 .2013 & 09.07.2013 \\
\hline & $08: 59: 11.22850$ & 09:00:16.428479 \\
\hline $\operatorname{meanSunAz}$ & 138.2 (degree) & 138.8 (degree) \\
\hline meanSunEl & 70.4 & 70.5 \\
\hline meanSatAz & 46.8 & 157.7 \\
\hline meanSatEl & 68.4 & 68.8 \\
\hline $\begin{array}{l}\text { MeanInTrack } \\
\text { ViewAngle }\end{array}$ & 15.3 & 15.7 \\
\hline $\begin{array}{c}\text { MeanCrossTrack } \\
\text { ViewAngle }\end{array}$ & 11.9 & 10.2 \\
\hline $\begin{array}{c}\text { MeanOffNadir } \\
\text { ViewAngle }\end{array}$ & 19.3 & 18.6 \\
\hline cloudCover & 0 & 0 \\
\hline productGSD & $0.50 \mathrm{~m}$ & $0.50 \mathrm{~m}$ \\
\hline
\end{tabular}




\subsection{Office and Field studies}

First of all; location of GCPs have been selected on the $1 / 25000$ scaled map. Nonresidental places have been selected for GCP. The aim of this is prevent of GCP from the destroying and, secondly to use for other different studies. Steel Frame has been made for the GCPs. Selected GCPs have been set up using of steel frame poured concrete on the field. GCPs have been painted white and black according to measurements below (figure 2).

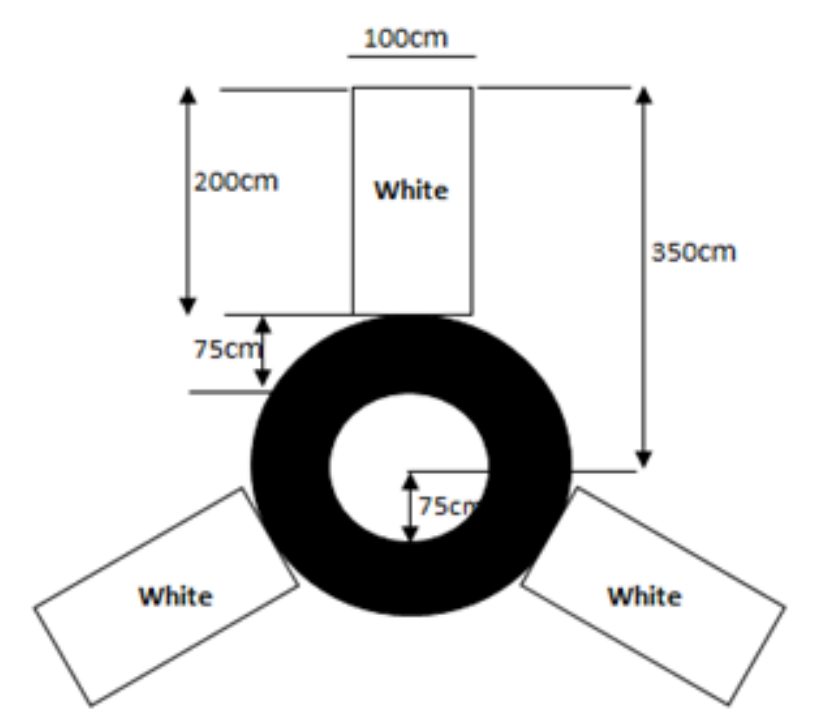

Figure 2: Dimensions of GCP

GCPs and satellite images which are marked in the field of view are given in figure 3 .

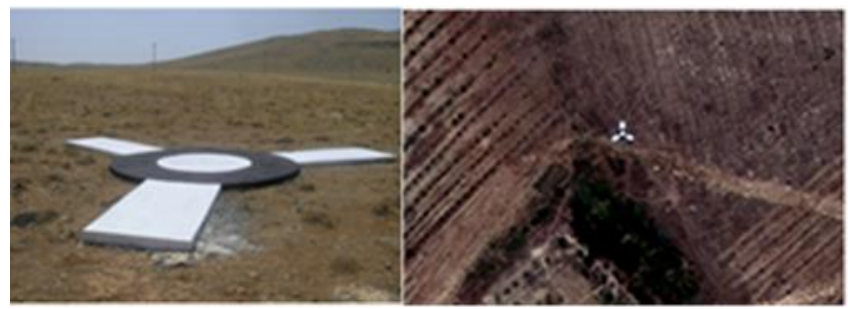

b

Figure 3: a) The GCP on the field

b) The GCP on the image

In addition, GCPs are marked with calcareous at difficult to reach areas and certain details are selected at settled areas. GCPs coordinates were measured by the method of CORS-TR.

Dual frequency Ashtech Promark 500 GNSS receiver was used at measurement. Sub $10 \mathrm{~cm}$ position accuracy with dualfrequency receiver can be obtained. Measurements are made in the two sessions and average values are calculated. Obtained coordinates are at ITRF system. For details of CORS-TR [12] and [13] can be found.

Erdas imagine software was used to evaluation of satellite image. 31 GCPs were used at block adjustment. For the suitable purpose of the study, First of all, suitable numbers and suitable distributed GCPs are used, then the number of suitable distributed points was reduced and reduced GCPs transformed to check points (figure 4). Control points are shown as $\Delta$ and check points are shown as O. The average error according to the results of block adjustment were given in table 3 .
Table 3: Calculated average errors according to $\mathrm{x}, \mathrm{y}, \mathrm{z}$ directions using different numbers control and check points

\begin{tabular}{|c|c|c|c|c|c|c|c|}
\hline \multicolumn{2}{|c|}{ Number of point } & \multicolumn{3}{c|}{ Control Point } & \multicolumn{3}{c|}{ Check Point RMSE(m) } \\
\hline \multirow{2}{*}{ Control } & \multirow{2}{*}{ Check } & $\mathrm{mx}$ & $\mathrm{my}$ & $\mathrm{mz}$ & $\mathrm{mx}$ & $\mathrm{my}$ & $\mathrm{mz}$ \\
\hline 31 & 0 & 0,34 & 0,23 & 0,25 & 0 & 0 & 0 \\
\hline 26 & 5 & 0,34 & 0,21 & 0,27 & 0,48 & 0,32 & 0,27 \\
\hline 21 & 10 & 0,32 & 0,21 & 0,30 & 0,43 & 0,28 & 0,29 \\
\hline 16 & 15 & 0,35 & 0,16 & 0,30 & 0,39 & 0,30 & 0,37 \\
\hline 11 & 20 & 0,33 & 0,19 & 0,35 & 0,48 & 0,27 & 0,47 \\
\hline 6 & 25 & 0,49 & 0,06 & 0,55 & 0,50 & 0,32 & 0,62 \\
\hline 5 & 26 & 0,53 & 0,17 & 0,63 & 0,55 & 0,26 & 0,65 \\
\hline 4 & 27 & 0,61 & 0,08 & 0,73 & 0,57 & 0,30 & 0,71 \\
\hline
\end{tabular}

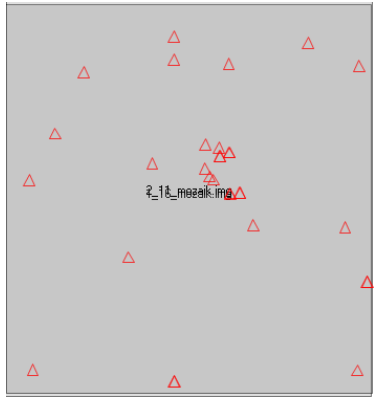

31 GCPs Control

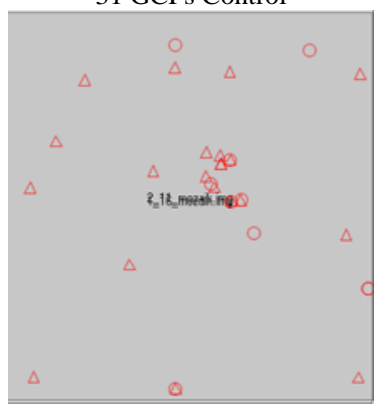

21 GCPs Control

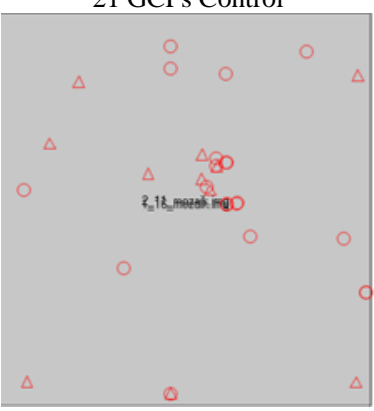

$11 \mathrm{GCPs}$ Control

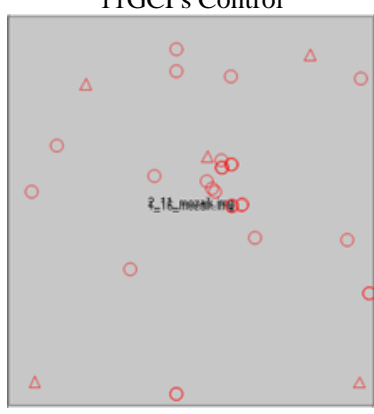

5 GCPs Control

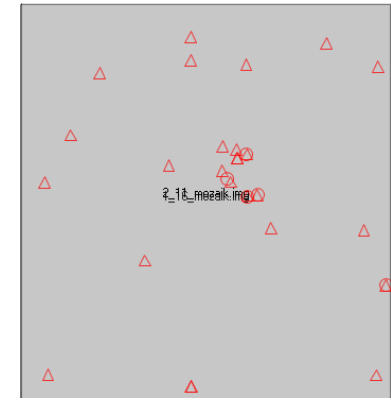

26 GCPs Control

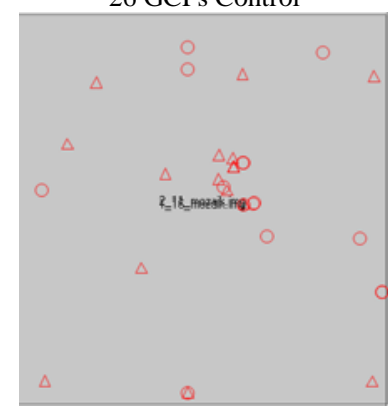

16 GCPs Contro



6 GCPs Control

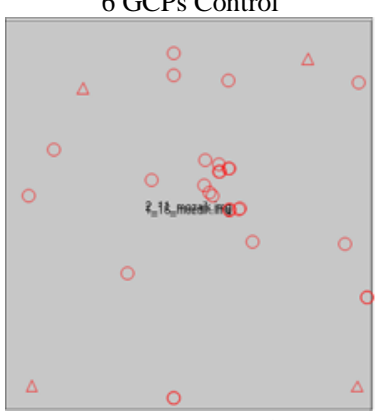

4GCPs Control
Figure 4: Distribution of control and check points

In the study area, when suitable distributed GCPs selected and other points are accepted as check points ; It can be seen that 
average errors aren't change a lot at $\mathrm{x}, \mathrm{y}, \mathrm{z}$ directions.

First of all, 5 GCPs control points, 26 GCPs check points are selected at suitable distributed. The others, control points are selected as non-suitable disributed (upper ,left right, cross etc.) (figure 5). Adjustment results are given at table 4.
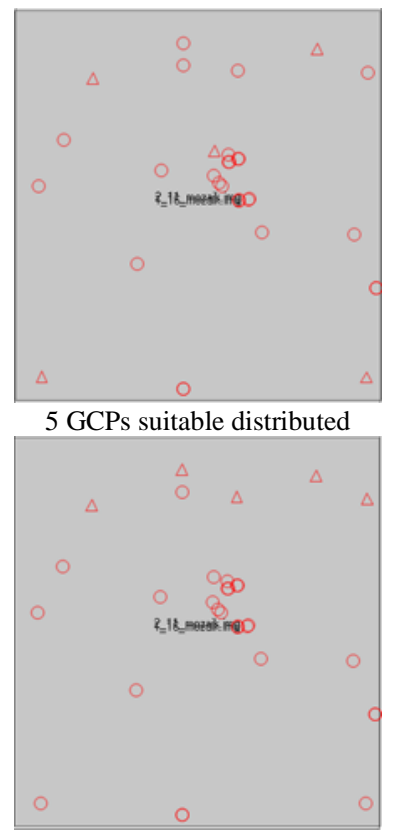

5 GCPs upper-horizontal
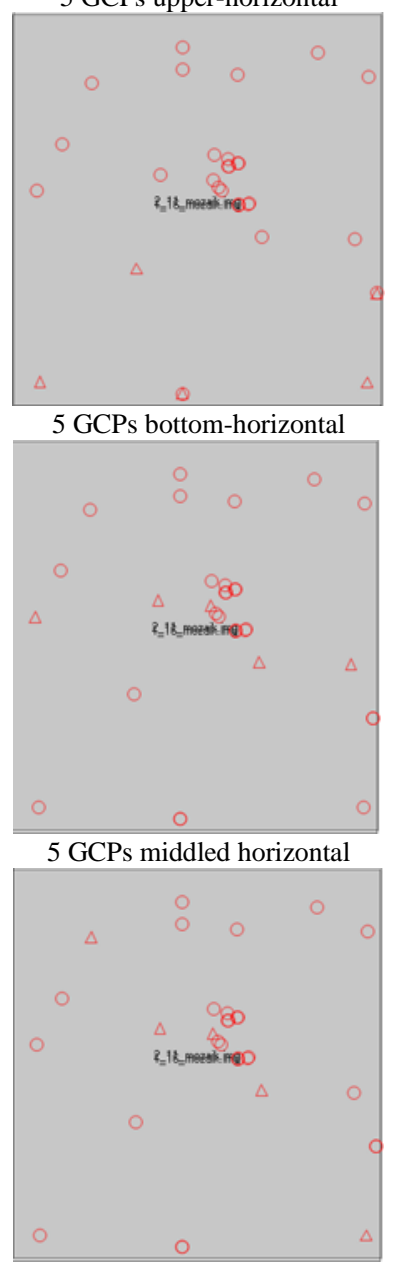

5 GCPs rightbottom-left upper



5 GCPs right-vertical



5 GCPs left-vertical

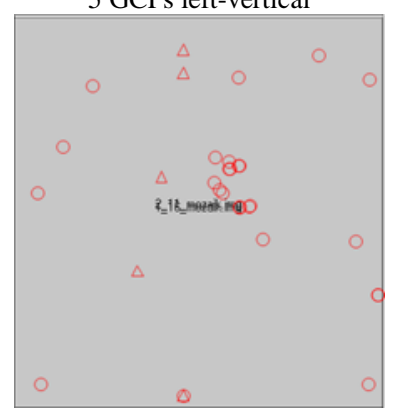

5 GCPs middle vertical

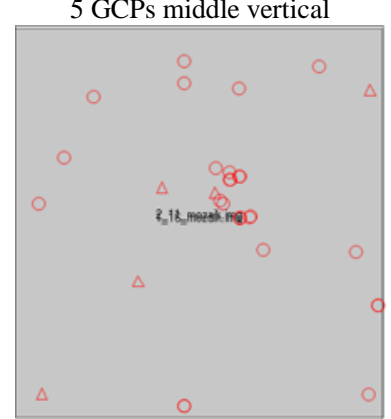

5 GCPs left bottom-right upper

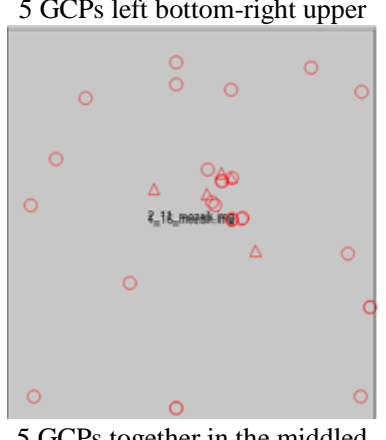

Table 4: Using non suitable distributed 5 control points obtained results according to $\mathrm{x}, \mathrm{y}, \mathrm{z}$ directions.

\begin{tabular}{|c|c|c|c|c|c|c|c|}
\hline \multicolumn{2}{|c|}{ Number of points } & \multicolumn{3}{|c|}{$\begin{array}{l}\text { Control Point } \\
\text { RMSE(m) }\end{array}$} & \multicolumn{3}{|c|}{$\begin{array}{l}\text { Check Point } \\
\text { RMSE(m) }\end{array}$} \\
\hline Control & Check & $\mathbf{m x}$ & my & $\mathbf{m z}$ & $\mathbf{m x}$ & my & $\mathbf{m z}$ \\
\hline $\begin{array}{c}5 \text { gcp } \\
\text { suitable } \\
\text { distributed }\end{array}$ & 21 & $\mathbf{0 , 5 3}$ & $\mathbf{0 , 1 7}$ & 0,63 & 0,55 & 0,26 & 0,65 \\
\hline \multicolumn{2}{|c|}{5 gcp right_vertical } & 0,32 & 0,12 & 0,72 & 0,40 & 0,54 & 8,65 \\
\hline \multicolumn{2}{|c|}{$5 \mathrm{gcp}$ upper-horizontal } & 0,44 & 0,16 & 0,64 & 0,57 & 0,26 & 2,00 \\
\hline \multicolumn{2}{|c|}{$5 \mathrm{gcp}$ left_vertical } & 0,48 & 0,08 & 0,62 & 0,57 & 0,34 & 1,69 \\
\hline \multicolumn{2}{|c|}{$\begin{array}{c}5 \mathrm{gcp} \\
\text { bottom_horizontal }\end{array}$} & 0,51 & 0,14 & 1,02 & 1,01 & 0,26 & 4,23 \\
\hline \multicolumn{2}{|c|}{5 gcp middle_vertical } & 0,49 & 0,13 & 0,61 & 0,71 & 0,37 & 4,19 \\
\hline \multicolumn{2}{|c|}{$\begin{array}{c}5 \mathrm{gcp} \\
\text { middle_horizontal }\end{array}$} & 0,46 & 0,17 & 0,72 & 0,50 & 0,27 & 2,89 \\
\hline \multicolumn{2}{|c|}{$\begin{array}{c}5 \mathrm{gcp} \text { cross, left } \\
\text { bottom_right upper }\end{array}$} & 0,23 & 0,14 & 0,84 & 0,45 & 0,33 & 3,58 \\
\hline \multicolumn{2}{|c|}{$\begin{array}{l}5 \mathrm{gcp} \text { cross right } \\
\text { bottom_left upper }\end{array}$} & 0,54 & 0,14 & 0,62 & 0,66 & 0,27 & 0,72 \\
\hline \multicolumn{2}{|c|}{$\begin{array}{l}5 \mathrm{gcp} \text { together in the } \\
\text { middle }\end{array}$} & 0,43 & 0,18 & 0,92 & 0,54 & 0,29 & 2,70 \\
\hline
\end{tabular}

According to the adjustment results, when non-suitable control points have been selected, average errors at $\mathrm{x}$ and $\mathrm{y}$ direction have been not effected a lot but $\mathrm{z}$ values have been significantly changed at check points [14].

\section{Conclusion}

In this study 9 july 2013 dated 0.5 resolution, stereo WoldView-2 pansharpened images have been used. One of the widely using areas of VHRS is producing and updating of maps.

To use as a map of VHRS images, geometric correction should be done certainly. Rectification process can be done without GCPs, but, using GCPs are increasing the accuracy of rectification. Numbers, distribution, shape and spatial accuracy of GCPs have effect on the rectification accuracy.

Time, cost and accuracy are an important factor at map production. If GCPs are marked more than needed, time and cost increase. This study has shown; rectification can be achieved at high accuracy with RPCs model and using suitable distribution of GCPs (4 or 5 GCPs). The effect of distribution of control points at the terrain have seen to be more effective than the effect of number of control points upon the adjustment results. Especially, $\mathrm{z}$ values are significantly changing at check points at rectification process when the non- suitable distributed GCPs have been used.

\section{Acknowledgements}

The authors wish to acknowledge for the cooperation and the financial assistance given by the Scientific Research Found (BAP) of Selcuk University.

Figure 5: Non suitable distributed control points 


\section{References}

[1] Dare, P., Pendlebury, N., Frase, C., 2002, "Digital Orthomosaics as a Source of Control For Geometrically Correction High Resolution Satellite_magery", Proceedings of the 23rd Asian Conference on Remote Sensing, Kathmoandu, No. 173, 2002,Nepal.

[2] Fraser, C., 2002, "Prospects For Mapping From HighResolution Satellite Imagery", Proceedings of the 23rd Asian Conference on Remote Sensing, Kathmoandu, No. 173, November 25-29, 2002,Nepal..

[3] Kadota, T. and Takagi, M., 2002, "Acquisition Method of Ground Control Points For High-Resolution Satellite Imagery", Proceedings of the 23rd Asian Conference on Remote Sensing, Kathmoandu, No. 173, November 25-29, 2002, Nepal.

[4] Dial, G. and Grodecki J., 2003, "Ikonos Stereo Accuracy Without Ground Control", ASPRS 2003 Annual Conference Procedings, May 2003, Anchorage,Alaska.

[5] Hanley, H. B. And Fraser C. S., 2001, "Geopositioning Accuracy of Ikonos Imagery; Indications from 2D Transformations, Photogrammetric Record, 17(98):317329.

[6] Ke Luong Chinh, 2006, Orthorectification Accuracies of VHRS Imagery Under the Characteristics of Ground Control Points, International Symposium on Geoinformatics for Spatial Infractructure Development in Earth and Allied Sciences.

[7] Yilmaz, H.M., Yakar., M. Mutluoglu, O. Yildiz, F., 2004, "Selection Of The Most Suitable Sizes Of Ground Control
Points In The Satellite Images",12-13 July, ISPRS Congress Istanbul.

[8] Mutluoglu,O., Yakar,M., Y1lmaz,H.,M., 2012, The Most Suitable Sizes Of Ground Control Points (Gcps) For World View2 FIG Working Week 2012 Knowing to manage the territory, protetect the environment, evaluate the cultural heritage Rome, Italy, 6-10 May.

[9] Padwick, C., Deskevich, M., Pacifici, F., Smallwood S., 2010, WorldView-2 pan-sharpening, ASPRS 2010, San Diego, California.

[10] Cheng, P., Chaapel, C., 2010, "Pan-sharpening and Geometric Correction WorldView-2 Satellite", GEOInformatic June 2010, 30-33. (Access Nisan 2010).

[11] URL:

WWW. DigitalGlobe.com_Core_Imagery_Product_Guide (Acces Nisan 2010 ).

[12] Yıldırım, Ö., Bakıcı, S. Cingöz, A., Erkan, Y., Gülal, E. Dindar, A. A., 2007, TUSAGA-AKTİF (CORS TR) Projesi Ve Ülkemize Katkıları, TMMOB Harita ve Kadastro Mühendisleri Odası, Ulusal Coğrafi Bilgi Sistemleri Kongresi,30 Ekim -02 Kasım, KTÜ, Trabzon.

[13] Kahveci, M., 2009, Gerçek Zamanlı Ulusal Sabit GNSS (CORS) Ağları ve Düşündürdükleri, hkm Jeodezi, Jeoinformasyon ve Arazi Yönetimi Dergisi 2009/1 Sayı 100.

[14] Mutluoglu, O., Yakar, M., Yilmaz, H.M, 2014, "Investigation Of Spatial Accuracy Of High-Resolution $(50 \mathrm{~cm})$ WORLVIEW-2 Satellite Images", Scientific Research Found (BAP) of Selcuk University (poject number 10401092). 